\title{
Safe Use of Glyphosate-containing Products in Aquatic and Upland Natural Areas ${ }^{1}$
}

\section{K. A. Langeland ${ }^{2}$}

Land and water managers who apply herbicides to control invasive plant species and other nuisance vegetation strive to minimize environmental impacts as a matter of policy and daily operations. It is, therefore, not surprising that concern has been expressed and many questions asked relative to recent publications by Relyea (2005a, 2005b, 2005c), which implicate use of glyphosate-containing herbicides in global decline of amphibians. The purpose of this article is to put these recent publications in perspective relative to aquatic and terrestrial natural area weed management and explain why land managers should continue to use glyphosate-containing products to protect managed habitats from weeds without concern for unreasonable adverse environmental impacts.

Relyea (2005a, 2005b, 2005c) conducted studies in "mesocosms" (tanks) to test the toxicity of a glyphosate-containing herbicide on amphibian species. Roundup Weed and Grass Killer, which contains $25.2 \%$ glyphosate (2.5 lb glyphosate a.i. per gallon) with an unknown amount of polyethoxylated tallowamine (POEA) surfactant, was applied to water in test tanks. This product is not registered for application to aquatic sites. In one of the studies, tests were conducted for 16 days with solution (water and initial herbicide concentration) renewal every four days (Relyea 2005a). Because application of product equivalent to $3.7 \mathrm{ppm}$ a.i. glyphosate would kill $90 \%$ to $100 \%$ of tadpoles of all six amphibian species tested, it was concluded that "Roundup with the POEA surfactant has the potential to play a major role in amphibian declines" (Relyea 2005a). This concentration represents the maximum that would occur when Roundup is broadcast applied at the highest label rate to water $15 \mathrm{~cm}$ (5.4 in) deep with no intercepting vegetation (an unlikely scenario). In another study (Relyea 2005b), an application of the maximum rate of a glyphosate-containing product was applied to three species of juvenile terrestrial amphibians to simulate a direct application to an agricultural field with no intercepting vegetation. Across all species, only $21 \%$ of the glyphosate-treated amphibians survived after one day, and it was concluded that "applying Roundup formulations containing the POEA surfactant to amphibian habitats has the potential to cause

1. This document is SS-AGR-104, one of a series of the Agronomy Department, Center for Aquatic and Invasive Plants, Florida Cooperative Extension Service, Institute of Food and Agricultural Sciences, University of Florida. Original publication date February 2006. Visit the EDIS Web Site at http://edis.ifas.ufl.edu.

2. Kenneth A. Langeland, professor, Agronomy Department, Center for Aquatic and Invasive Plants; Florida Cooperative Extension Service, Institute of Food and Agricultural Sciences, University of Florida, Gainesville, FL 32610.

The use of trade names in this publication is solely for the purpose of providing specific information. UF/IFAS does not guarantee or warranty the products named, and references to them in this publication does not signify our approval to the exclusion of other products of suitable composition. 
substantial mortality to many amphibian species" (Relyea 2005b).

Data presented in Table 1 show the wide range of toxicities to forms of glyphosate and glyphosate-containing products. Roundup is 10 to 100 times more toxic to indicator species than either the parent glyphosate acid or Rodeo, which contains the isopropylamine salt of glyphosate. POEA, the surfactant contained in the original Roundup, was the most toxic surfactant of 19 tested on bluegill sunfish (Haller and Stocker 2003). Several studies have reported toxicity levels of glyphosate products to amphibian species (Edgington et al. 2004, Howe et al. 2004, Mann and Bidwell 1999, Wojtaszek et al. 2004, Perkins et al. 2000). Toxicity of Roundup to aquatic organisms because of the POEA surfactant was known by Monsanto when Roundup was originally labeled in 1978 and data were provided to the Environmental Protection Agency (EPA). This is why the formulation was not registered for aquatic uses; nor are glyphosate-containing products with POEA now registered for aquatic use. Most glyphosate-containing products that are registered for aquatic use are manufactured without surfactant (Touchdown Pro, the exception, contains a different surfactant) so that the applicator can use one of the many commercial surfactant products available that have low toxicity to aquatic organisms and instructions for aquatic applications. While the contents of commercial surfactants is proprietary information, they are regulated and only contain ingredients that are approved by EPA or the Food and Drug Adminstration.

When applying glyphosate-containing herbicides that do not contain POEA, Relyeas studies are not applicable. When applying glyphosate-containing products that contain no surfactant and registered for application to vegetation growing in water, addition of only those surfactants with aquatic use directions should be used. This will prevent unreasonable adverse impacts to aquatic organisms.

Assumptions of Relyea's experimental design exaggerate the potential impact of glyphosate-containing products relative to application for control of invasive plants in upland natural areas and in wetlands. Because glyphosate-containing products that are labeled only for terrestrial application are not applied to aquatic sites, concern for exposure to aquatic organisms is an issue of drift or contact with temporary pockets of water. Concentration much lower than that resulting from maximum application rates are expected. When spot treatments of herbicide using hand-held equipment are made, the applicator has direct control of where the spray solution is applied and little, if any, herbicide comes in contact with standing water. Likewise, direct application of spray solution to amphibians is unlikely. Broadcast application of glyphosate-containing products with POEA are rarely made to upland natural areas because of potential damage to non-target plant species, and if broadcast applications are made, vegetation is present that intercepts a majority of the spray solution. Exposure of test organisms for 16 days with solution renewal every four days is not consistent with realistic exposure under vegetation management practices. Under field conditions active ingredients and adjuvants are broken down or sequestered through natural processes. Renewal of test solution every four days is equivalent to four separate applications. Field studies to assess impacts under representative natural conditions, and monitoring studies conducted under conditions relevant to product use indicate that glyphosate herbicides registered for terrestrial application are not likely to result in adverse effects to amphibians when used according to label directions (Wojtaszek et al. 2004, Thompson et al. 2004).

When applying glyphosate-containing products containing POEA to upland natural areas, there is a wide margin of safety to amphibians and other wildlife relative to toxic levels and realistic potential exposure levels. Applicators who apply glyphosate-containing products according to instructions on the herbicide label and on the surfactant label will have an acceptable margin of safety to wildlife. Land managers should continue to use glyphosate-containing products to protect managed habitats from weeds without concern for unreasonable adverse environmental impacts, as originally determined by regulatory agencies when these products were considered for registration. There are no data that suggest the use of glyphosate-containing herbicide products is 
responsible for global declines in amphibian populations.

\section{Literature Cited}

Edgington, A. N., P.M. Sheridan, G. R. Stephenson, D. G. Thompson and H. J.

Boermans. 2004. Comparative effects of $\mathrm{pH}$ and Vision ${ }^{\circledR}$ Herbicide on two life stages of four anuran amphibian species. Environ. Toxicol. Chem. 23:815-822.

Haller, W. T. and R. K. Stocker. 2003. Toxicity of 19 adjuvants to juvenile Lepomis macrochirus (bluegill sunfish). Environ. Toxicol. Chem. 22:615-619.

Howe, C. M., M. Berrill, B. D. Pauli, C. C. Helbing, K. Werry and N. Veldhoen. 2004. Toxicity of glyphosate-based pesticides to four North American frog species. Environ. Toxicol. Chem. 23:1928-1938.

Mann, R. M. and J. R. Bidwell. 1999. The toxicity of glyphosate formulations to four species of southwestern Australian frogs. Arch. Environ. Contam. Toxicol. 36:193-199.

Perkins, P. J., H. J. Boemans, G. T. Stephenson. 2000. Toxicity of glyphosate and triclopyr using the frog embryo teratogenesis assay - Xenopus. Environ. Toxicol. Chem. 19:940-945.

Relyea, R. A. 2005a. The lethal impacts of Roundup and predatory stress on six species of North American tadpoles. Arch. Environ. Contam. Toxicol. 48:351-357.

Relyea, R. A. 2005b. The lethal impact of Roundup on aquatic and terrestrial amphibians. Ecological Applications 15:1118-1124.

Relyea, R. A. 2005c. The impact of insecticides, and herbicides on the biodiversity and productivity of aquatic communities. Ecological Applications 15:618-627.

Thompson, D. G., B. F. Wojtaszek, B. Staznik, D. T. Chartrand, and G. R. Stephenson, 2004. Chemical and biomonitoring to assess potential acute effects of Vision ${ }^{\circledR}$ Herbicide on native amphibian larvae in forest wetlands.

Environ. Toxicol. Chem. 23:843-849.

Vencill, W. K. ed. 2002. Herbicide Handbook. Weed Science Society of America, Lawrence, KS. 493 pp.

Wojtaszek, B. F., B. Staznik, D. T. Chartrand, G. R. Stephenson, and D. G. Thompson. 2004.

Environ. Toxicol. Chem. 23:832-842. 
Table 1. Toxicity of glyphosate and glyphosate-containing herbicides to aquatic organisms when applied in different forms (Vencill 2002; Touchdown Pro data provided by Syngenta Crop Protection, Inc.).

\begin{tabular}{|c|c|c|c|c|}
\hline \multirow[t]{2}{*}{ Toxicity } & Glyphosate acid & Touchdown Pro & Rodeo & Roundup \\
\hline & \multicolumn{4}{|c|}{$\mathrm{mg} / \mathrm{L}$} \\
\hline Daphnia 48 hr LC50 & 780 & 160 & 930 & $5.3-37$ \\
\hline Bluegill sunfish 96 hr LC50 & 120 & $>180$ & $>1000$ & $5.8-14$ \\
\hline Rainbow trout 96 hr LC50 & 86 & 180 & $>1000$ & $8.2-26$ \\
\hline
\end{tabular}

